\title{
Carbon Nanotube Chopped Fiber for Enhanced Properties in Additive Manufacturing
}
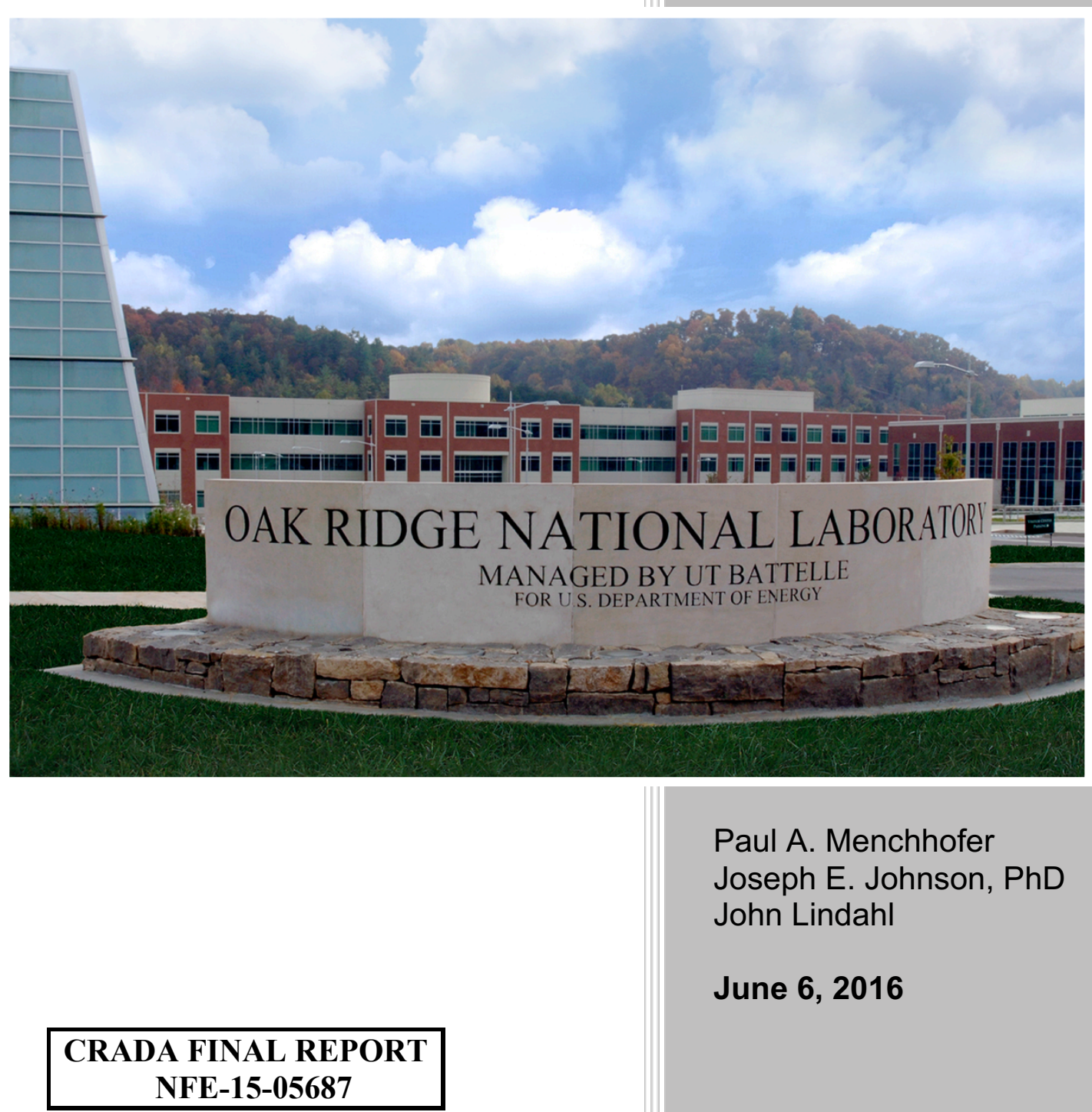

Paul A. Menchhofer Joseph E. Johnson, PhD John Lindahl

June 6, 2016

\section{Approved for Public Release.} Distribution is Unlimited. 


\title{
DOCUMENT AVAILABILITY
}

Reports produced after January 1, 1996, are generally available free via US Department of Energy (DOE) SciTech Connect.

Website http://www.osti.gov/scitech/

Reports produced before January 1, 1996, may be purchased by members of the public from the following source:

\author{
National Technical Information Service \\ 5285 Port Royal Road \\ Springfield, VA 22161 \\ Telephone 703-605-6000 (1-800-553-6847) \\ TDD 703-487-4639 \\ Fax 703-605-6900 \\ E-mail info@ntis.gov \\ Website http://www.ntis.gov/help/ordermethods.aspx
}

Reports are available to DOE employees, DOE contractors, Energy Technology Data Exchange representatives, and International Nuclear Information System representatives from the following source:

Office of Scientific and Technical Information

PO Box 62

Oak Ridge, TN 37831

Telephone 865-576-8401

Fax 865-576-5728

E-mail reports@osti.gov

Website http://www.osti.gov/contact.html

This report was prepared as an account of work sponsored by an agency of the United States Government. Neither the United States Government nor any agency thereof, nor any of their employees, makes any warranty, express or implied, or assumes any legal liability or responsibility for the accuracy, completeness, or usefulness of any information, apparatus, product, or process disclosed, or represents that its use would not infringe privately owned rights. Reference herein to any specific commercial product, process, or service by trade name, trademark, manufacturer, or otherwise, does not necessarily constitute or imply its endorsement, recommendation, or favoring by the United States Government or any agency thereof. The views and opinions of authors expressed herein do not necessarily state or reflect those of the United States Government or any agency thereof. 
Materials Science and Technology Division Advanced Manufacturing Office

\title{
CARBON NANOTUBE CHOPPED FIBER FOR ENHANCIED PROPERTIES IN ADDITIVE MANUFACTURING \\ Authors \\ Paul A Menchhofer \\ Joseph E. Johnson, Ph.D. \\ John Lindahl
}

Date Published:

June 6, 2016

\author{
Prepared by \\ OAK RIDGE NATIONAL LABORATORY \\ Oak Ridge, Tennessee 37831-6283 \\ managed by \\ UT-BATTELLE, LLC \\ for the \\ US DEPARTMENT OF ENERGY \\ under contract DE-AC05-00OR22725
}

Approved For Public Release 


\section{CONTENTS}

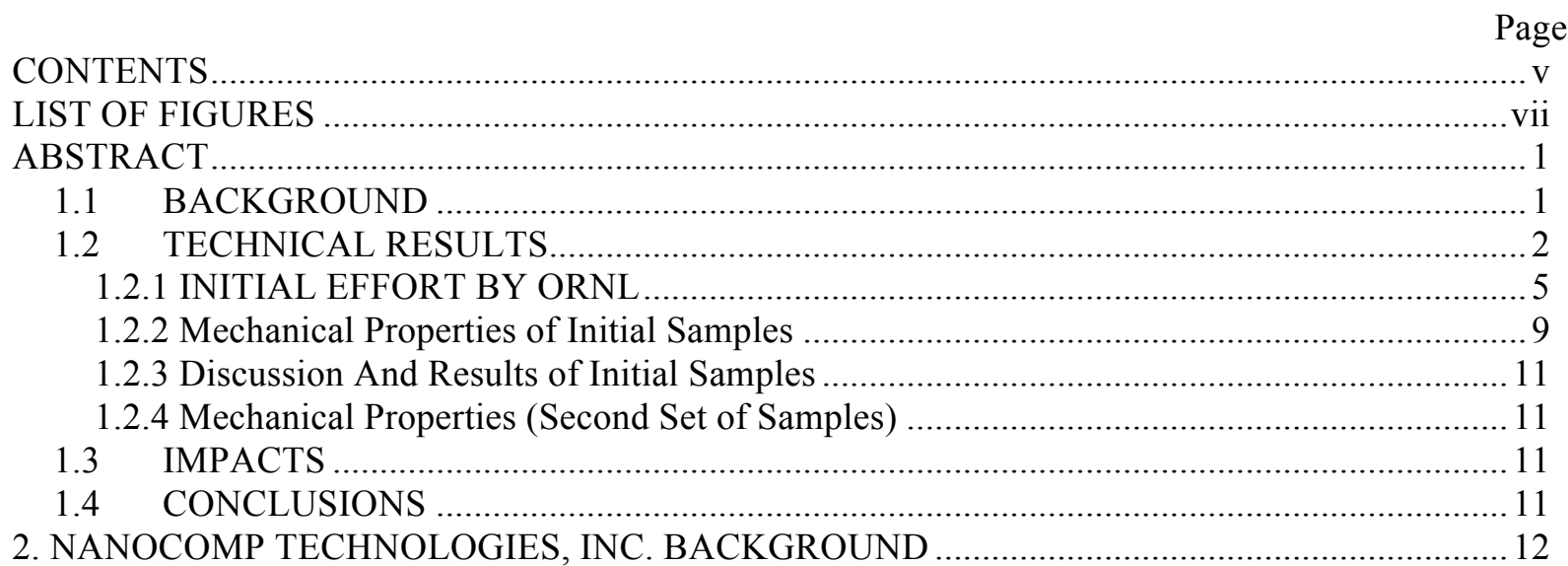




\section{LIST OF FIGURES}

Fig. 1. Carbon nanotube pulp in a bag container. 2

Fig.2. SEM micrograph of Nanocomp carbon nanotube chopped fibers (pulp) (magnification 100,000x). 3

Fig. 3. Light micrograph of Nanocomp carbon nanotube chopped fibers (pulp)(magnification 100x). 3

Fig. 4. Equivalent particle size distribution for CNT pulp fibers. .................................................... 4

Fig. 5. CNT-ABS filaments (diameter $1.7 \mathrm{~mm}$ ) showing thickness uniformity................................. 4

Fig. 6. Light microscope cross-section of a 1\% CNT-ABS filament (diameter $1.7 \mathrm{~mm}$ ) showing CNTs

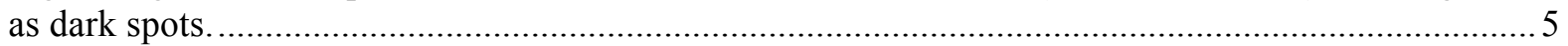

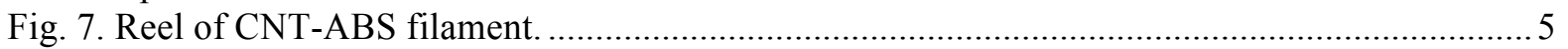

Fig. 8. SEM image of as received CNTs which appear to be in bundles or ropes................................. 6

Fig. 9. Higher magnification of as received CNTs shows "rope" comprised of agglomerated

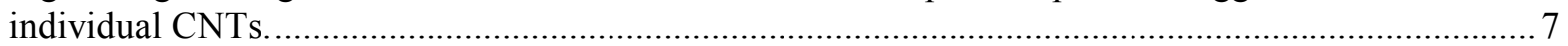

Fig. 10. CNT-ABS filament initially with poor consistency. ............................................................ 7

Fig. 11. Tensile bar (ABS with 1 wt. \% CNTs.) This bar was not tested due to its poor quality............ 8

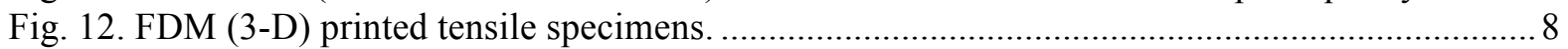

Fig. 13. Fracture surface ABS with $0.5 \%$ CNTs. Note agglomerates of non-dispersed CNTs. ........... 9

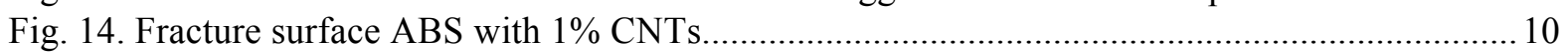

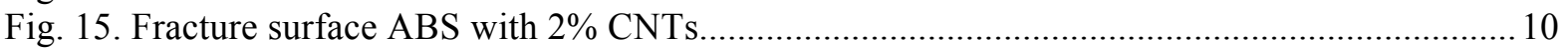

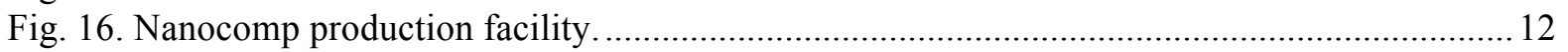




\begin{abstract}
Nanocomp Technologies, Inc. is working with Oak Ridge National Laboratory to develop carbon nanotube (CNT) composite materials and evaluate their use in additive manufacturing (3D printing). The first phase demonstrated feasibility and improvements for carbon nanotube (CNT)acrylonitrile butadiene styrene (ABS) composite filaments use in additive manufacturing, with potential future work centering on further improvements. By focusing the initial phase on standard processing methods (developed mainly for the incorporation of carbon fibers in ABS) and characterization techniques, a basis of knowledge for the incorporation of CNTs in ABS was learned. The ability to understand the various processing variables is critical to the successful development of these composites. From the degradation effects on ABS (caused by excessive temperatures), to the length of time the ABS is in the melt state, to the order of addition of constituents, and also to the many possible mixing approaches, a workable flow sequence that addresses each processing step is critical to the final material properties. Although this initial phase could not deal with each of these variables in-depth, a future study is recommended that will build on the lessons learned for this effort.
\end{abstract}

\title{
1. CARBON NANOTUBE CHOPPED FIBER FOR ENHANCIED PROPERTIES IN ADDITIVE MANUFACTURING
}

This phase 1 technical collaboration project (MDF-TC-2014-066) began on November 4, 2015 and the first phase was completed on April 31, 2016. The collaboration partner Nanocomp Technologies, Inc. is a small business. Nanocomp Technologies, Inc. produced CNT-acrylonitrile butadiene styrene (ABS) composite filaments that were evaluated by Oak Ridge National Laboratory, showing feasibility for use in additive manufacturing, but with a need for further improvements.

\subsection{BACKGROUND}

Nanocomp Technologies, Inc. is a small enterprise with 80 employees. The company produces carbon nanotubes using a chemical vapor deposition (CVD) process. The carbon nanotube technology was declared a critical technology, essential to the US national defense in accordance with section 303(a)(5) of the Defense Production Act, 50 U.S.C. 2093(a)(5) which authority was delegated to the Secretary of Defense by Executive Order 12919 and further delegated to the Under Secretary of Defense, signed by the latter, honorable Dr. Ashton B. Carter, on December 19, 2010. Nanocomp Technologies, Inc. is an 11 year old start-up company based in Merrimack, N.H.

Carbon nanotubes (CNT) provide enhanced mechanical, electrical, and thermal properties to polymeric composites. Properties include tensile strength, elasticity, electromagnetic interference/ Electron Spin Resonance (EMI/ESR) shielding, and thermal resistivity. Nanocomp is working with several polymer and traditional polymer process companies to determine benefits for CNTcomposites. Internally, Nanocomp has an extrusion system that generates CNT chopped fiber composite filaments or pellets for further processing. The company also has a small 3D printer used for making a limited amount of small parts, since additive manufacturing (AM) warrants itself to limited runs, with high tech materials. Oak Ridge National Laboratory, (ORNL) is a technology leader in fused deposition modeling (FDM) and evaluation, as well as material assessment and development assistance. Thus, Nanocomp's materials technologies com need for making FDM parts. The objective of phase one of the project was to show print feasibility for CNT-ABS filaments and establish criteria to improve performance to get to a commercial state. 
The challenge addressed in this project was to take CNT pulp, having significantly different properties compared to polymers and be able to 1) disperse the pulp in a homogenous manner into ABS or other polymers creating a $1.7 \mathrm{~mm}$ strand and 2) be able to print using an FDM device. If feasibility of printing is achieved, then most 3D parts could be generated with the CNT-composite, and benefit from CNT properties. The Nanocomp team was challenged with part 1, while the ORNL team was charged with part 2.

\subsection{TECHNICAL RESULTS}

ORNL evaluated a number of CNT-ABS composites. The ABS polymer used was Cyclolac ${ }^{\circledR}$ EX-75 sourced from Sabic. The carbon nanotubes fibers used in the study were composed of thousands of individual nanotubes of $\sim 10 \mathrm{~nm}$ diameter and length of $\sim 1000 \mathrm{um}$ that were adhered together by van der Waals forces and also intertwined. The resulting pulp had an equivalent sphere diameter of $\sim 100 \mathrm{um}$. Additionally, a compatibilizer (surfactant-like material) was also added to the second lot of CNT chopped fibers. The role of the compatibilizer was to improve dispersion of the CNTs in the ABS matrix. The goal being that the more dispersed the CNTs are throughout the polymer, the greater improvement in properties. Additionally, improved dispersion translates into improved AM processing, as there are fewer large agglomerates which may clog or build up at the printer nozzle. Pictures of the carbon nanotube chopped fibers or pulp are shown in figures 1) bag of pulp, 2) scanning electron microscopy (SEM) of CNT pulp fibers and 3) light microscope picture of CNT pulp fibers.

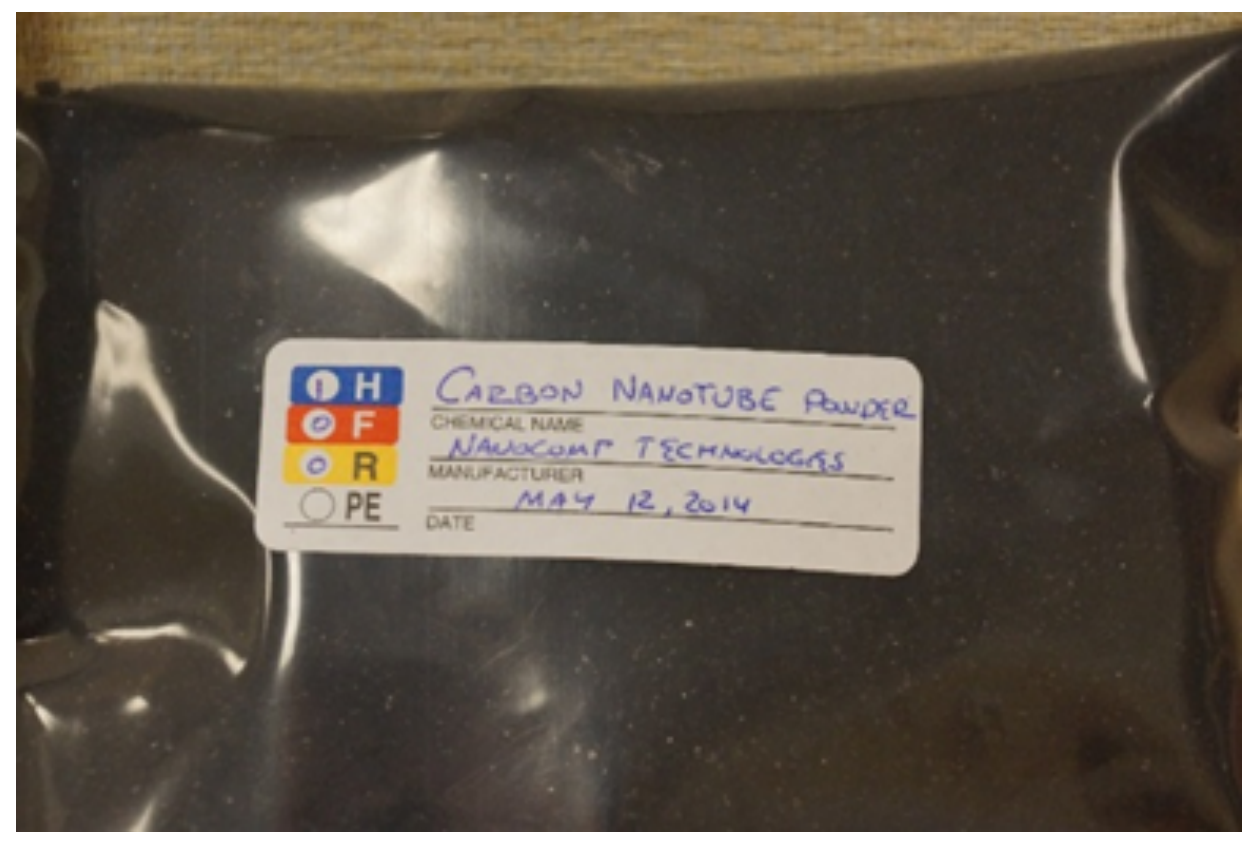

Fig. 1. Carbon nanotube pulp in a bag container. 


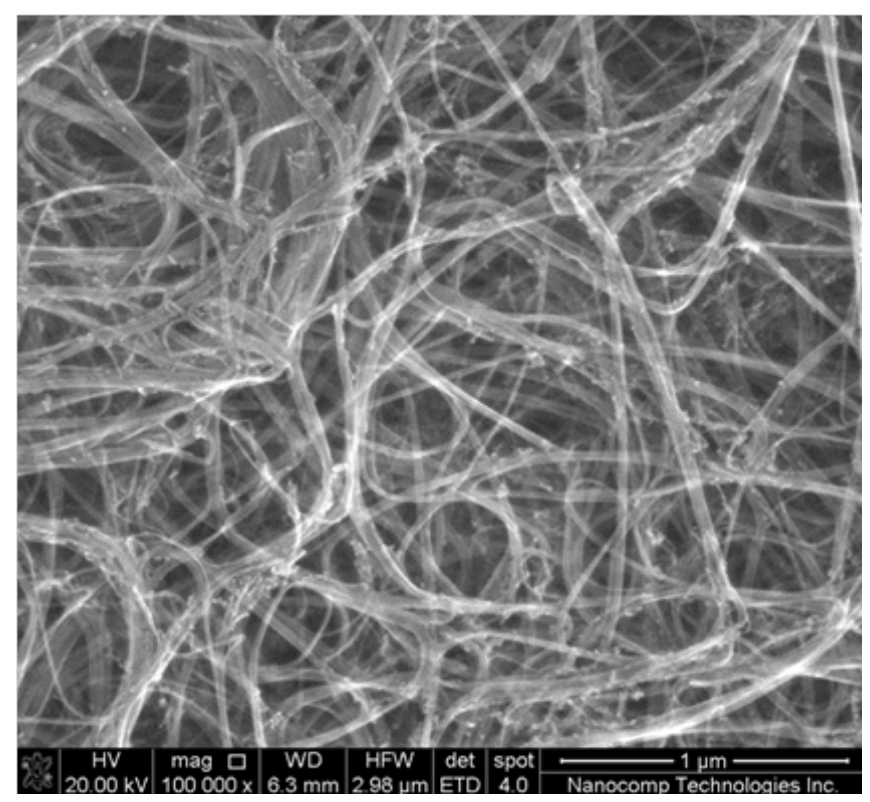

Fig.2. SEM micrograph of Nanocomp carbon nanotube chopped fibers (pulp) (magnification 100,000x).

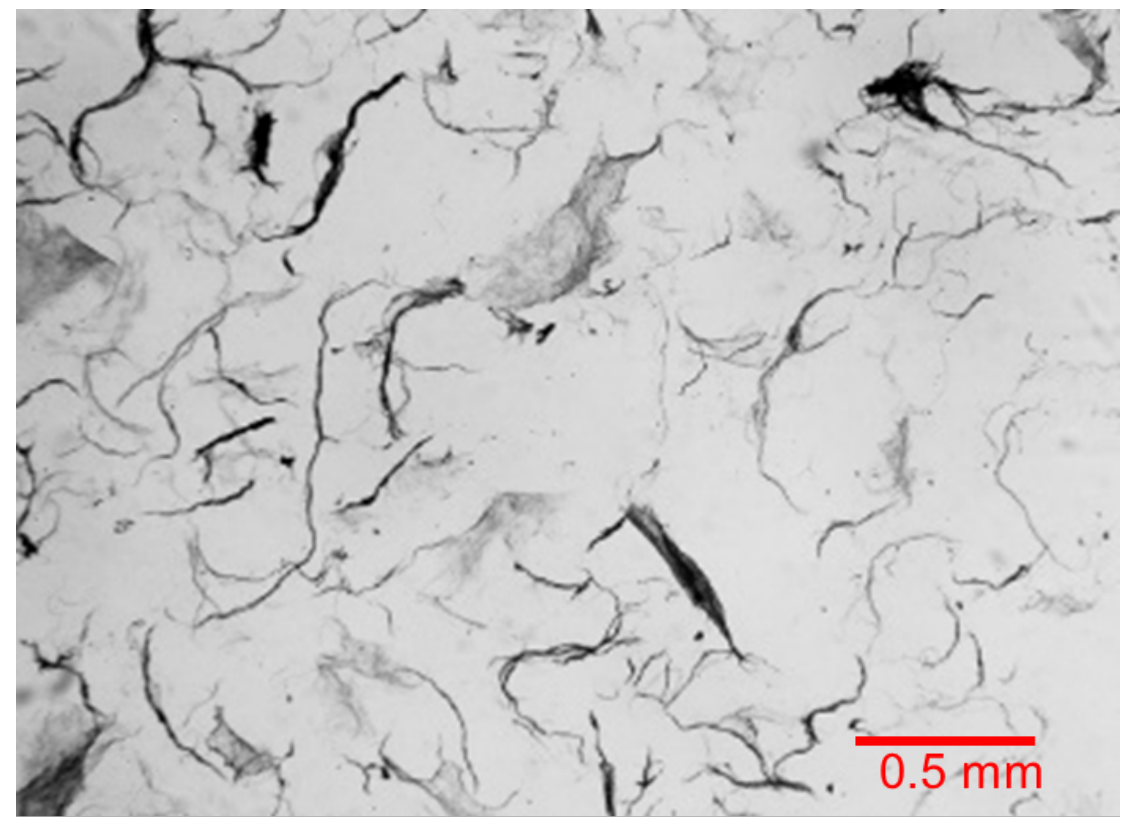

Fig. 3. Light micrograph of Nanocomp carbon nanotube chopped fibers (pulp)(magnification 100x).

The chopped fibers were made by dispersing Nanocomp's CNT sheet material. The sheets were made using a CVD process involving a floating catalyst, and heating hydrocarbon fuels at elevated temperatures in an oxygen-free environment. The CNT pulp was characterized using a FlowCam ${ }^{\circledR}$ Analyzer that gives a distribution of equivalent particle size (diameter) based on length and width of fibers and calculated from optical parameters. Properties of the CNT fibers used in the study are shown in Fig. 4. 


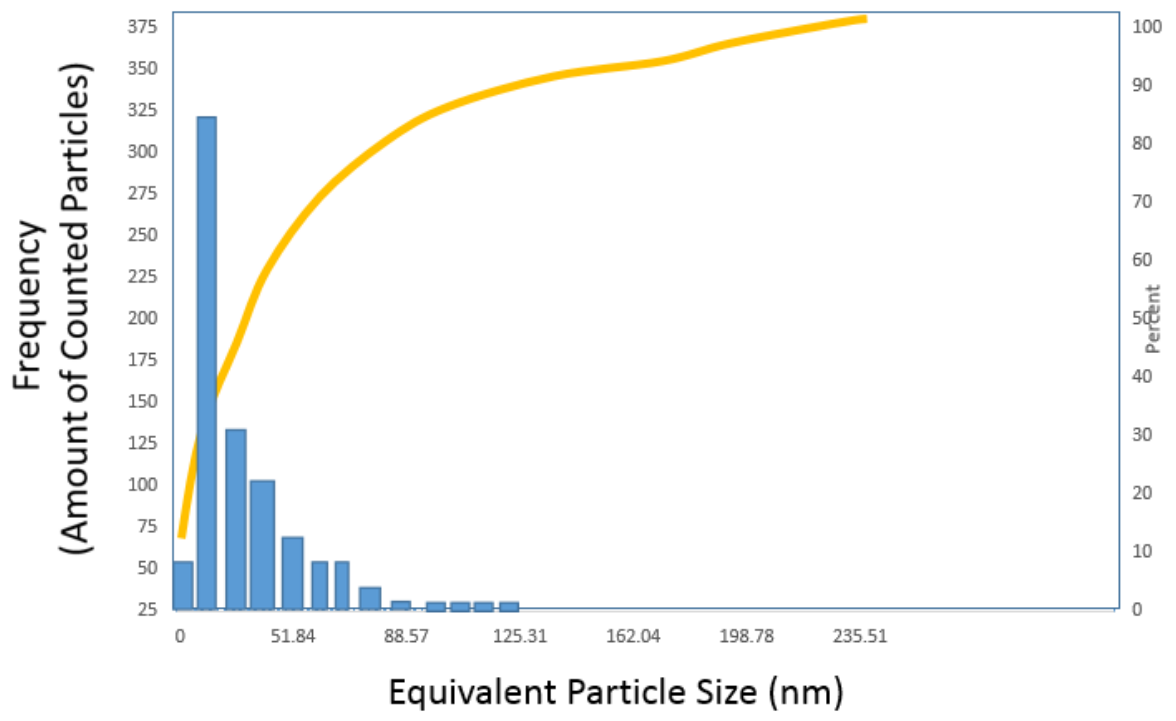

Fig. 4. Equivalent particle size distribution for CNT pulp fibers.

The CNT pulp was added to the ABS in a twin screw extruder (Thermo Scientific, Pharma 11 Model) to form $1.7 \mathrm{~mm}$ filaments of the composite. The concentrations of CNTs were $0 \%, 0.5 \%, 1 \%$ and 2\%. Representative CNT-ABS filaments are relatively uniform in thickness as shown in Figs. 57. Also, the filaments were tested for resistance using a resistivity meter (Desco, Model 1787). All filaments showed similar readings as the pure polymer (1e12 ohm-sq) indicating that the CNTs were below their perculation point. Typically, the perculation point for CNT in ABS starts around 3\% CNT loading, so these results were not surprising.

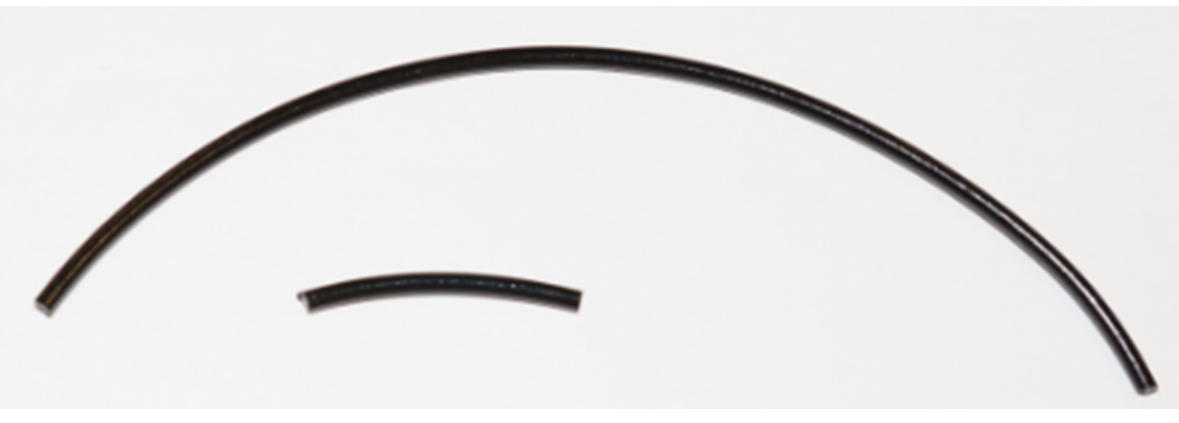

Fig. 5. CNT-ABS filaments (diameter $1.7 \mathrm{~mm}$ ) showing thickness uniformity. 


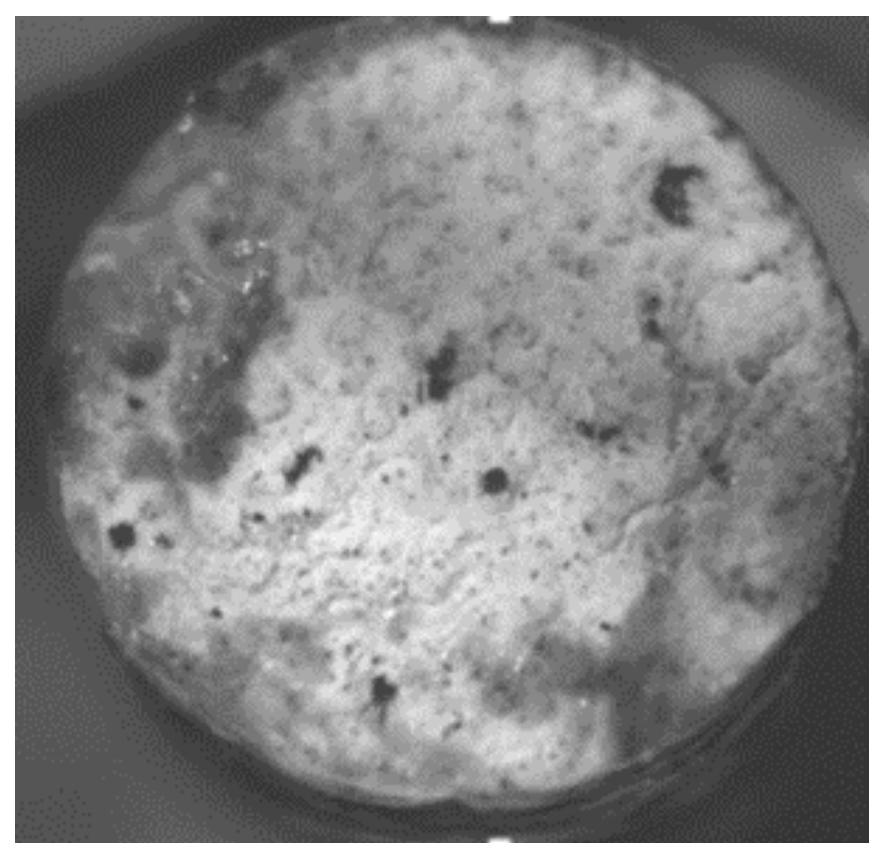

Fig. 6. Light microscope cross-section of a $1 \%$ CNT-ABS filament (diameter $1.7 \mathrm{~mm}$ ) showing CNTs as dark spots.

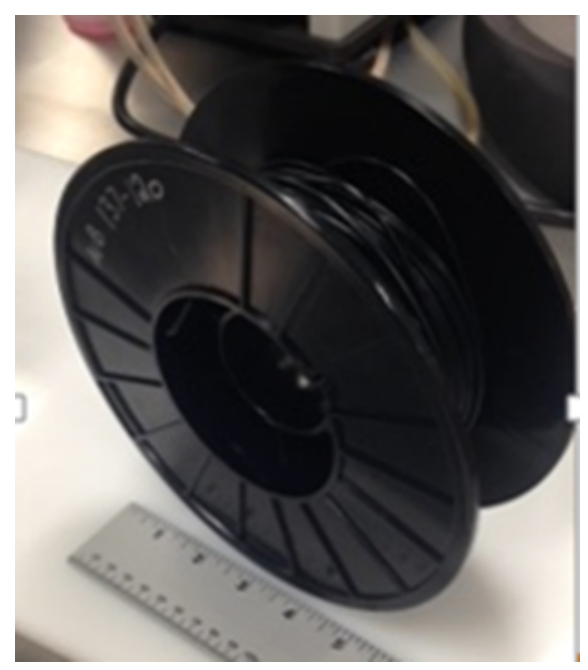

Fig. 7. Reel of CNT-ABS filament.

\subsubsection{Initial effort by ORNL}

As received CNTs (figs 8 \& 9) were examined via SEM and found to be in long "rope" or bundled / agglomerated condition. The extent of entanglement can be appreciated (figs 8 \& 9) and when considering the goals of the project were to disperse individual CNTs homogeneously within the ABS matrix, the challenge becomes obvious. It also became obvious that the methods for combining and processing the components would be challenging particularly when considering all potential effects caused by processing. Initially, samples of CNT reinforced ABS composite mixtures were prepared by first dissolving the ABS into either acetone or tetrahydrofuran (THF) (Table 1). The initial trials using acetone were abandoned in preference for THF. After dissolving the ABS into THF, the ABS solution was combined with a second solution (dispersion of CNTs in THF), followed by combination and co-mixing by sonication for 10 minutes (to yield 1 and $2 \mathrm{wt}$. \% concentrations of 
CNTs in the final compounds. The solution mixing was followed by evaporation of the THF to yield a solid mixture which could be subsequently heated to soften, and further mixed in a high shear (Brabender Intelli-Torque Plasti-Corder) prep-mixer at $60 \mathrm{rpms}$ at $220^{\circ} \mathrm{C}$, for 5 minutes, followed by filament production @ $195^{\circ} \mathrm{C}$, and final 3-D printing at $\sim 205^{\circ} \mathrm{C}$. Tensile test specimens (dog-bones shown in figures 11 and 12) were printed by feeding the extruded filaments through a commercial desktop FDM Solidoodle 3 unit. Although the printing was completed, there were variations (figure 10 ) in the filament diameters, (due to CNT agglomerates) which occasionally occluded the printer tip. (Note CNT agglomerates in figures 8 and 9). Tensile test procedure ASTM standard D633 was employed for testing five "Type-V" tensile bars at $0.001 \mathrm{in} / \mathrm{s}$. for each composition.

Table 1. Initial compositions of ABS composite mixtures.

\begin{tabular}{l|c|c|c|c|}
$\begin{array}{l}\text { CNT reinforced ABS } \\
\text { Composites }\end{array}$ & Vol\% CNTs & Wt.\%CNTs & Vol.\%ABS & Wt.\%ABS \\
\hline $\begin{array}{l}\text { PM-12-115-1 @ 1 wt.\% } \\
\text { (industry) CNTs via acetone } \\
\text { solvation }\end{array}$ & $0.58 \%$ & $1.00 \%$ & 99.42 & $99.00 \%$ \\
\hline $\begin{array}{l}\text { PM-12-110- @ 2 wt.\% } \\
\text { (industry) CNTs via acetone } \\
\text { solvation }\end{array}$ & $1.15 \%$ & $2.00 \%$ & $98.85 \%$ & $98.00 \%$ \\
\hline
\end{tabular}

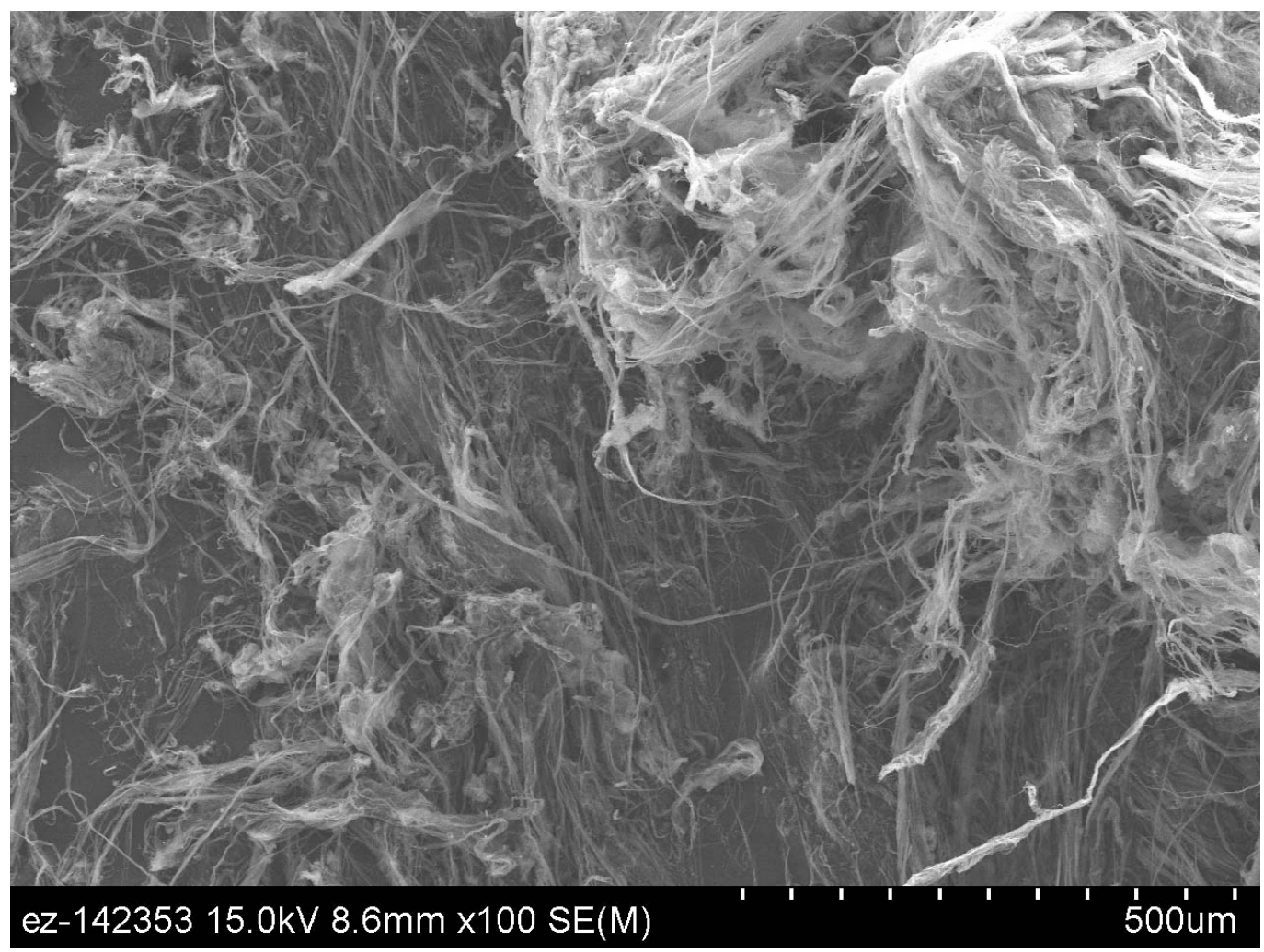

Fig. 8. SEM image of as received CNTs which appear to be in bundles or ropes. 


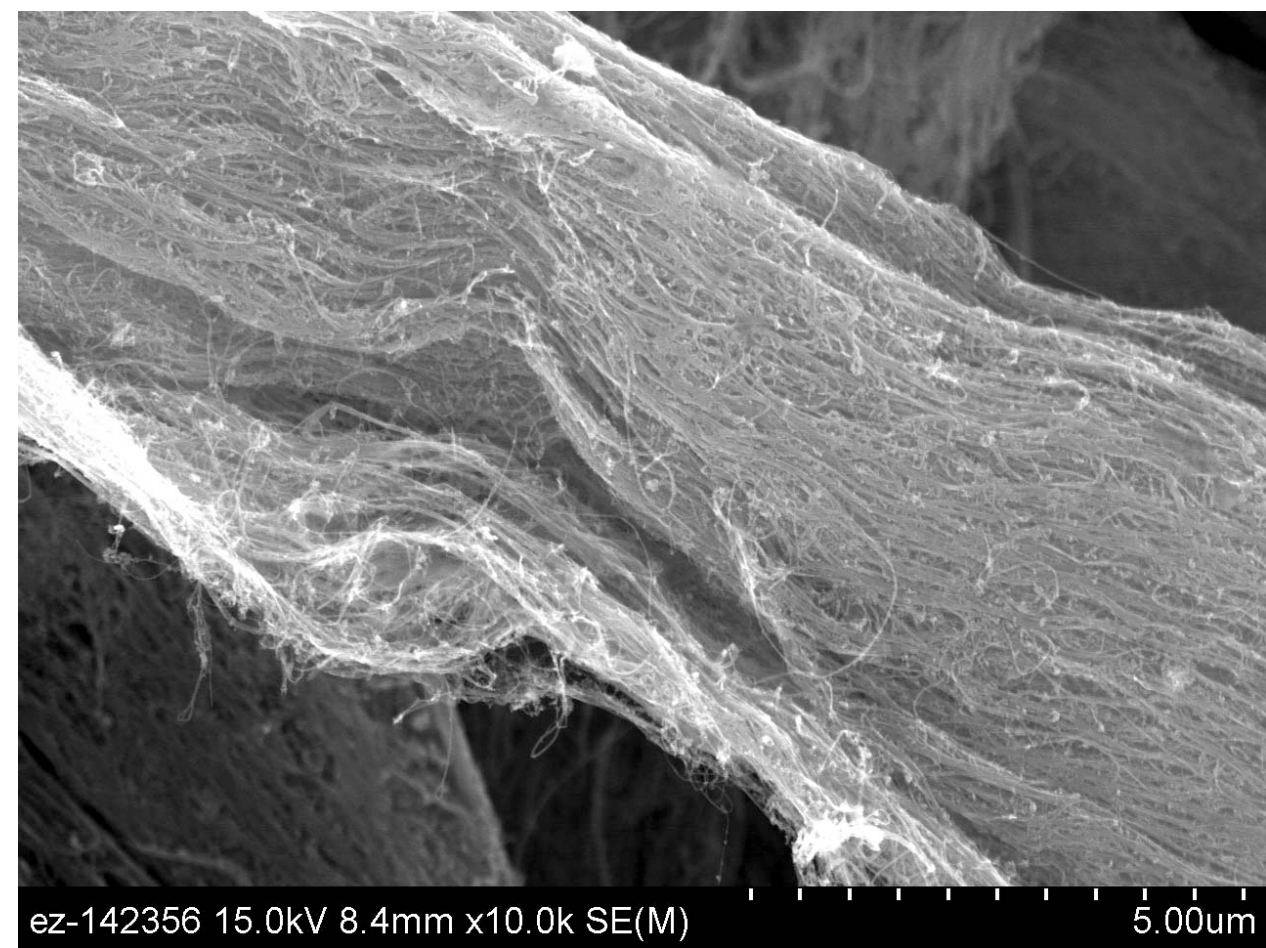

Fig. 9. Higher magnification of as received CNTs shows "rope" comprised of agglomerated individual CNTs.

Figure 10 is representative for the ORNL produced filament used for the initial tensile bars, which had inconsistencies due to their undispersed agglomerates.

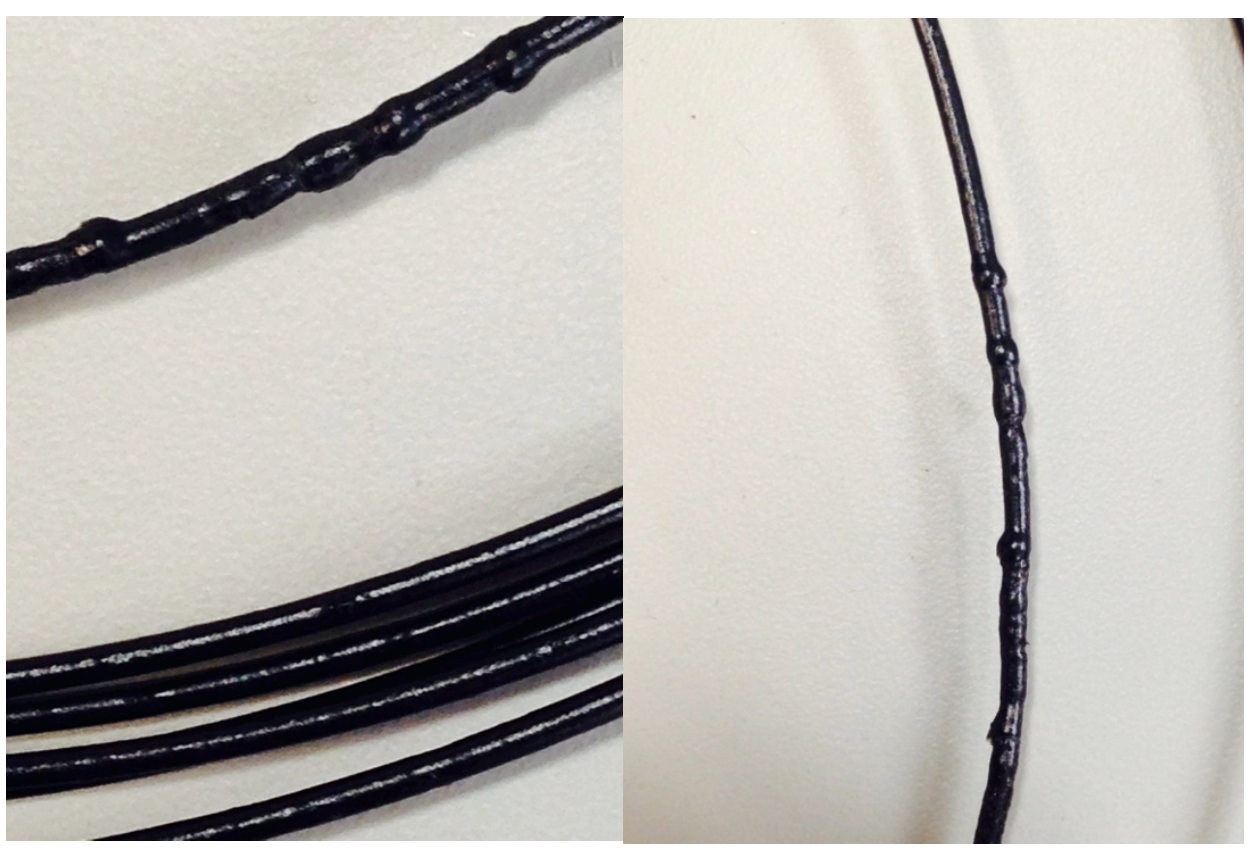

Fig. 10. CNT-ABS filament initially with poor consistency. 


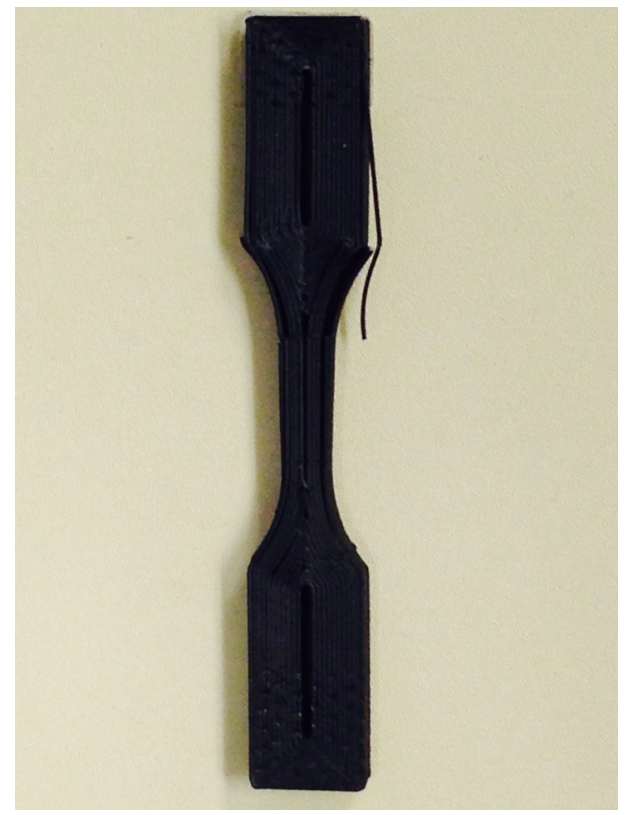

Fig. 11. Tensile bar (ABS with 1wt. \% CNTs.) This bar was not tested due to its poor quality.

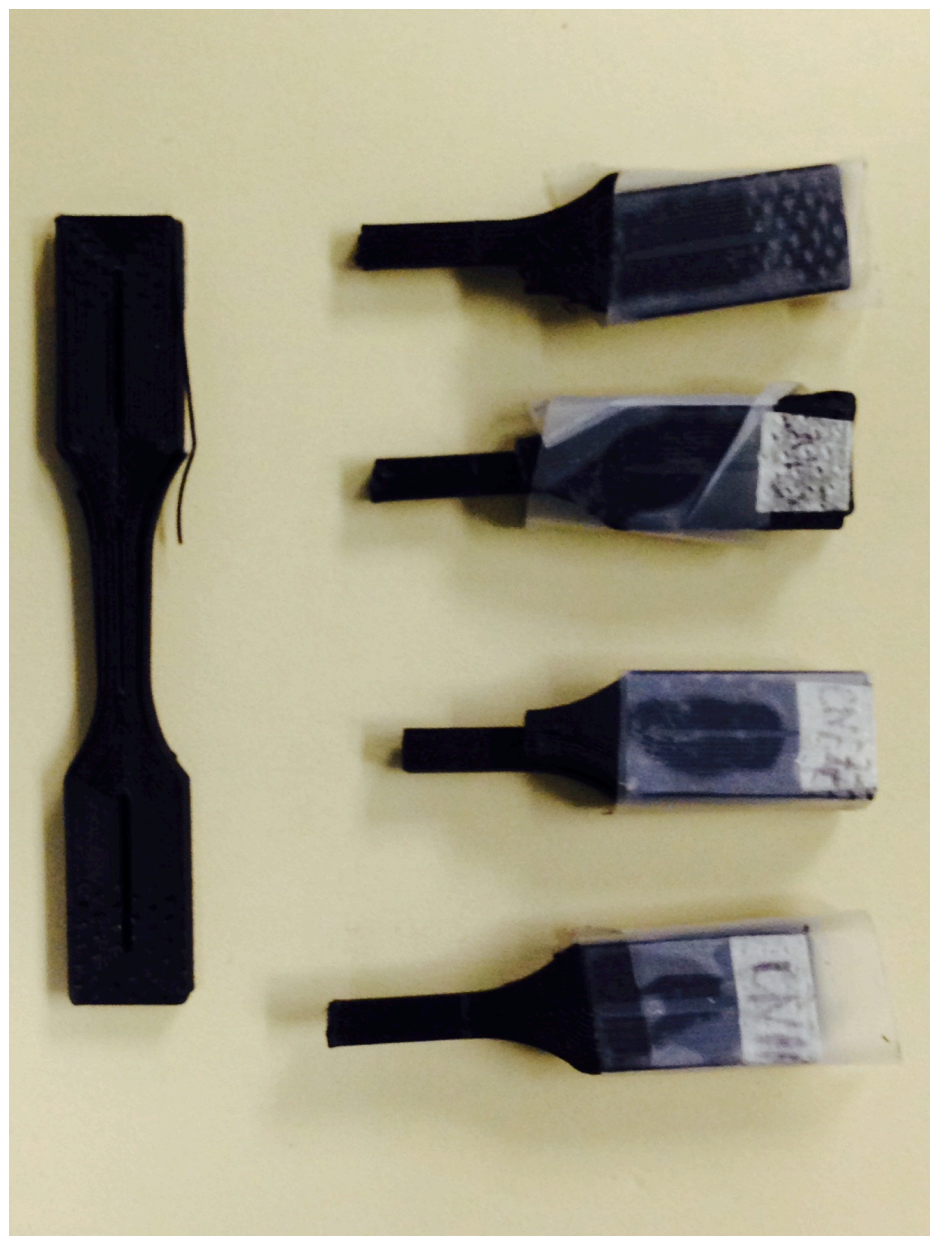

Fig. 12. FDM (3-D) printed tensile specimens. 


\subsubsection{Mechanical properties of initial samples}

Table 2. Mechanical Properties (initial samples).

\begin{tabular}{|c|c|c|c|}
\hline Sample & Mechanical Properties & $\begin{array}{l}\text { Modulus } \\
\text { (Gpa) }\end{array}$ & Strength (Mpa) \\
\hline Control & ABS PM-12-107-2 (CONTROL) & 1.83 & 36.50 \\
\hline $\begin{array}{c}\text { PM- } \\
12-125\end{array}$ & PM-12-125 Industry CNTs added @1wt\% & 1.92 & 30.65 \\
\hline
\end{tabular}

As can be seen from the initial samples data, the strength of the CNT loaded samples were inferior to the ABS control sample, (likely due to the large agglomerates which act as weakening flaws for the composite). The modulus however increased slightly for the CNT loaded sample, (which is typical for CNT loaded polymers). Following the initial effort, additional CNT-loaded filaments were produced by Nanocomp for three compositions $(0.5 \%, 1 \%, 2 \%)$ CNTs, and were used to print more tensile specimens. The following SEM characterization study was conducted for these.

\subsubsection{SEM Characterization of second sample set}

After printing and tensile testing of the second set of Type $\mathrm{V}$ tensile specimens, SEM was conducted on the resulting cross-section fracture surfaces of the tested tensile bars for each composition $(0.5 \%, 1 \%, 2 \%)$. Images were captured of the cross-sectioned (fracture surfaces) for each composition and are included in figures 13-15.

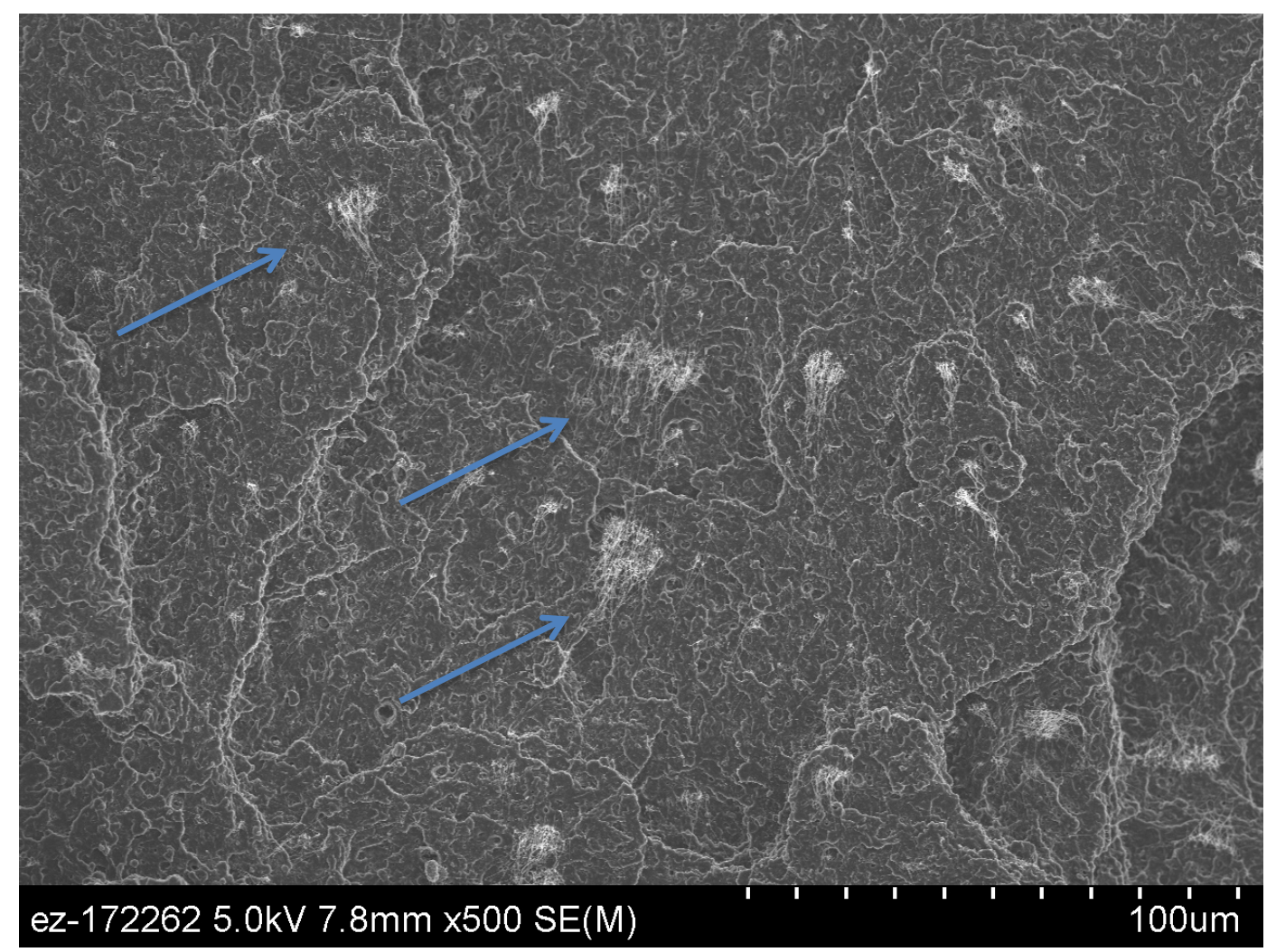

Fig. 13. Fracture surface ABS with $0.5 \%$ CNTs. Note agglomerates of non-dispersed CNTs. 


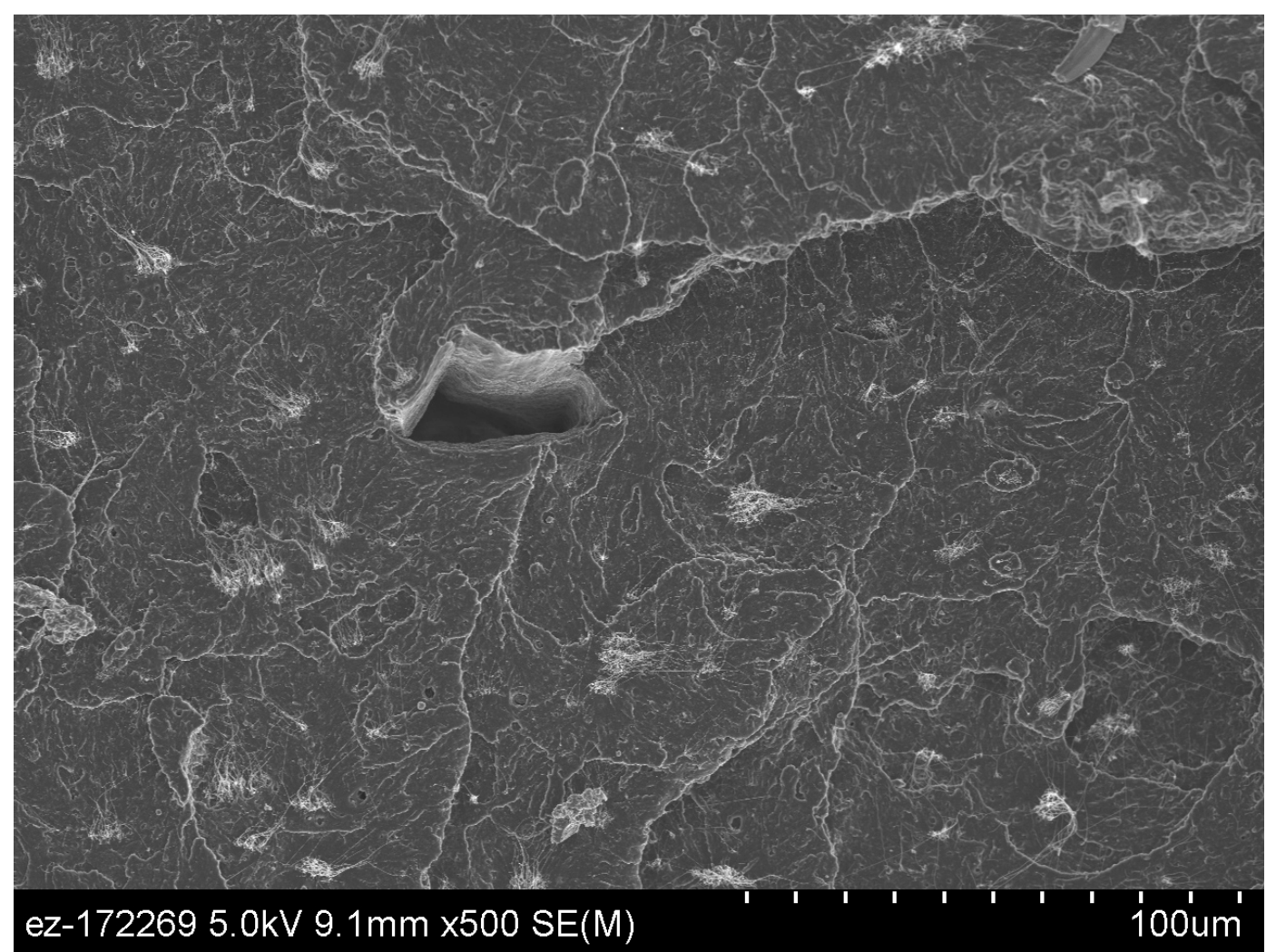

Fig. 14. Fracture surface ABS with 1\% CNTs.

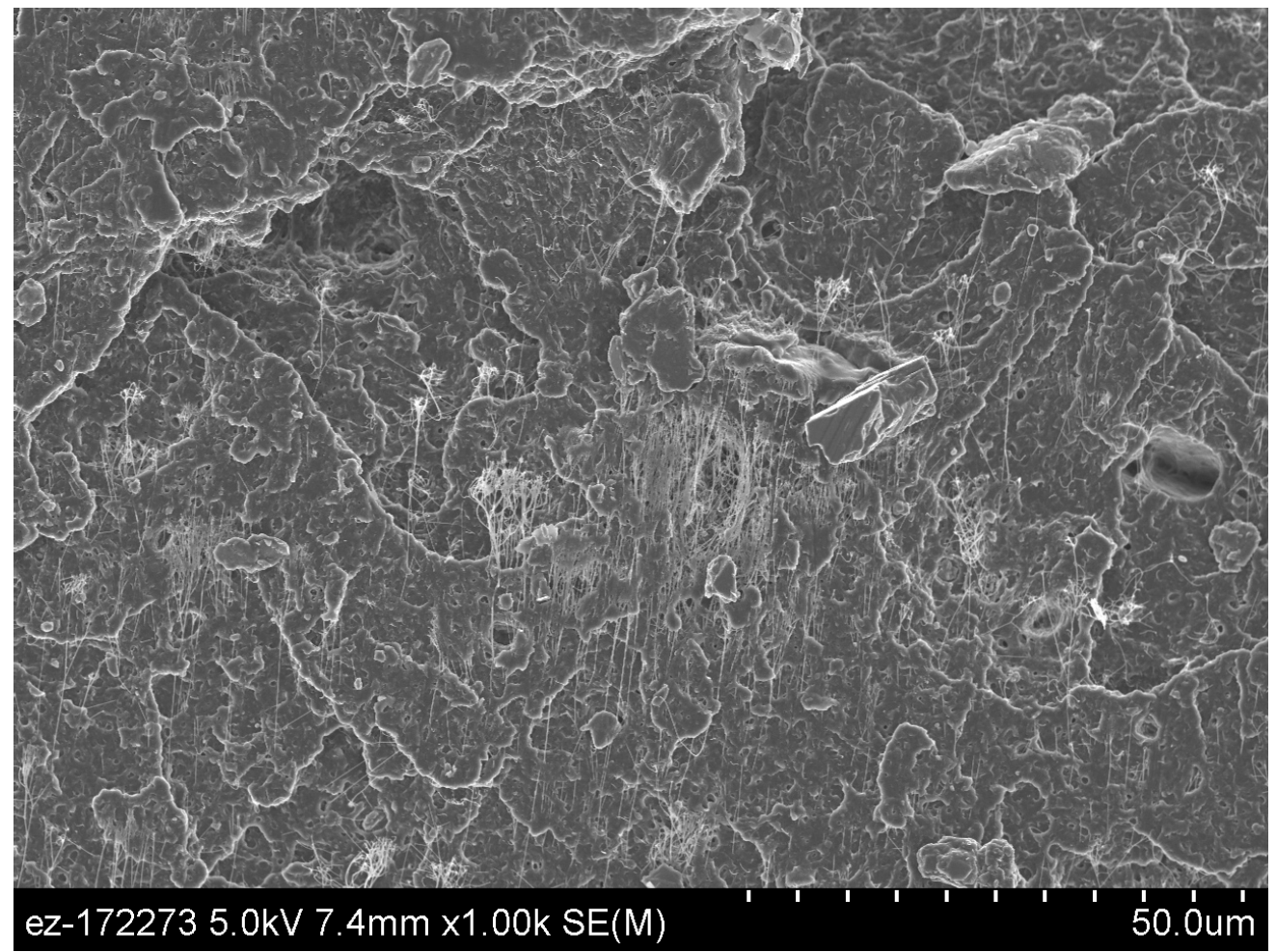

Fig. 15. Fracture surface ABS with 2\% CNTs. 


\subsubsection{Discussion and results of initial samples}

Agglomerates of CNTs remain in the final samples as determined by SEM, thus emphasizing the need for further optimization in integration, mixing, and dispersion of the CNTs into the precursor and print filament. The CNTs provided by Nanocomp (figures 8 and 9) were tightly bundled and proved difficult to disperse, although samples prepared with THF (as solvent) proved better for printing than the early attempts which utilized acetone as the solvent.

\subsubsection{Mechanical properties (Second set of samples)}

The tensile strength and modulus were measured for the second set of 3-D printed "Type-V" tensile specimens. Again, tensile test procedure ASTM standard D633 was employed for testing five "Type-V" tensile bars at $0.001 \mathrm{in} / \mathrm{s}$. for each composition containing $0.5,1.0$ and $2.0 \%$ CNTs. The following table shows the values measured. The second set of composite filaments were prepared by Nanocomp without the use of solvents, and were prepared simply by combining ABS pellets with the as-received CNTs within a (Thermo Scientific) twin screw melt extruder.

As expected, the modulus increased with increasing CNT content, although the highest strength was measured for the sample composition containing $1 \%$ CNTs.

Table 3. Mechanical Properties (Second set of samples).

\begin{tabular}{|l|c|c|}
\hline Sample & Modulus (Gpa) & Strength (Mpa) \\
\hline ABS Control & 2.18 & 39.19 \\
\hline $0.5 \%$ CNT & 2.52 & 44.19 \\
\hline $1 \%$ CNT & 2.74 & 45.92 \\
\hline $2 \%$ CNT & 2.83 & 39.19 \\
\hline
\end{tabular}

\subsection{IMPACTS}

This project demonstrated that Nanocomp's CNTs could be successfully combined with ABS to produce a $1.7 \mathrm{~mm}$ diameter filament form, which was subsequently extruded by a commercial 3D desktop (Solidoodle 3) printer. This work demonstrated the potential for utilizing CNTs as a reinforcing phase in composite materials for polymer additive manufacturing.

Although significant knowledge was gained, the dispersion of CNTs in ABS has not yet been optimized, and this Phase 1 study failed to provide major improvements in the mechanical properties for the prepared compositions. However, there has been progress towards the development of processing knowledge as well as a better understanding of the processing steps that affect the final material properties of CNT reinforced ABS composites, and the specific processing variables which could affect improvements in the future. In this Phase 1 of the project, the knowledge acquired from this initial study provides the critical foundation for more in-depth future efforts.

\subsection{CONCLUSIONS}

The objective of the initial project was to show print feasibility for CNT-ABS filaments, which was successfully demonstrated. As a preliminary Phase I, the knowledge acquired from this initial study establishes a basis for future efforts directed at processing development towards the eventual goal of offering advantages to the advanced manufacturing sector, specific to the area of Additive manufacturing known as 3-D polymer printing. As a result of this study, the partner has acquired a 
better understanding of the complexities associated with the necessary processing steps and recognizes the challenges for the targeted goals as well as the need for more in-depth research efforts where each processing step would be systematically studied in order to optimize the potential for overall improvements in the final composites.

\subsection{NANOCOMP TECHNOLOGIES, INC. BACKGROUND}

Nanocomp started in 2004 with only 3 employees in a 500 square-foot space in an old mill building in Lebanon, NH. It was in this modest facility that the first government contract for unlimited length carbon nanotubes was awarded. There was substantial technical and customer development in the following year leading to the opening of an 11,000 square-foot facility in Concord, NH with more equipment and capacity. This facility housed the first automated carbon nanotube based sheet machines in the world as well as the early generation yarn machines. As material demand continued to rise, Nanocomp acquired both government and private investments, enabling the move to its current facility in 2012 .

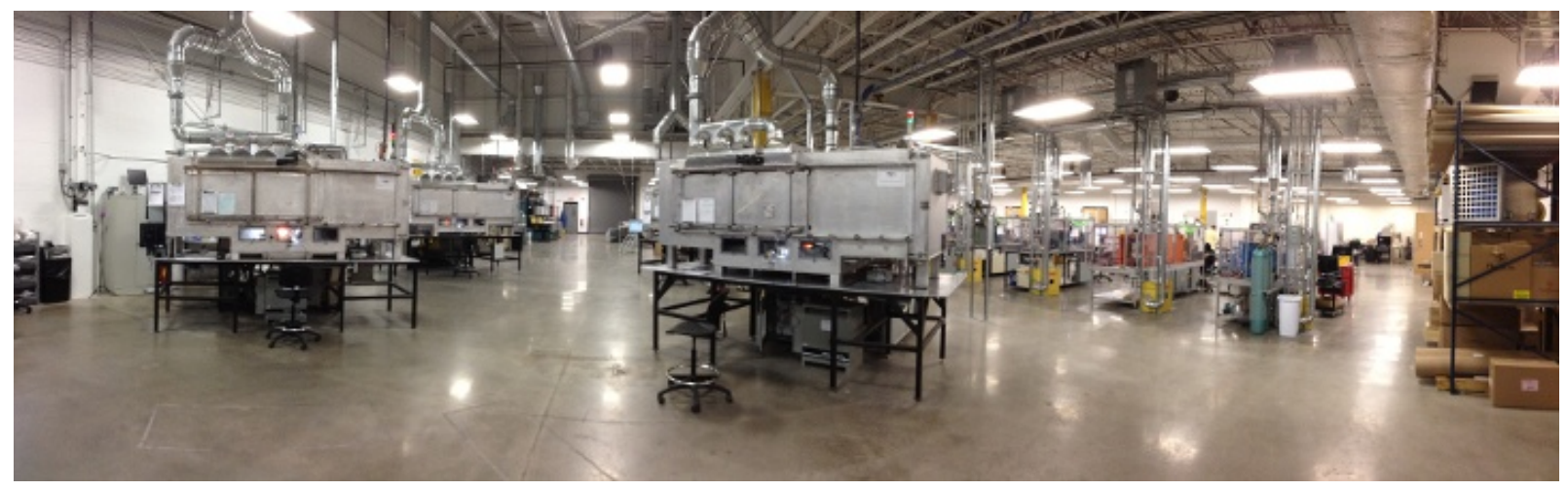

Fig. 16. Nanocomp production facility.

Today, in Merrimack, NH, Nanocomp has 80 employees and operates three production shifts daily in its 60,000 square-foot facility, with plans to add an additional 40,000 square-feet in the next couple of years. 